BLS 32, No 2 2006. DOI: http://dx.doi.org/10.3765/bls.v32i2.3490

(published by the Berkeley Linguistics Society and the Linguistic Society of America)

\title{
Composite Tone in Mian Noun-Noun Compounds
}

\author{
SEBASTIAN FEDDEN \\ University of Melbourne ${ }^{1}$
}

\section{Introduction}

This paper deals with composite tone in Mian noun-noun compounds. The term "composite tone" is used here for a combination of the two tonal melodies for which the respective noun roots are lexically specified. The autosegmental analysis proposed in this paper assumes that composite tone melodies are assigned to the whole word after compounding and identifies word stress as the decisive prosodic feature which determines tone assignment.

Mian is a Papuan language of the Ok family (Healey 1964, Wurm 1982), spoken in Telefomin District of Sandaun Province in Papua New Guinea by approximately 1,400 people. In terms of larger-order affiliation, the Ok languages belong to the Trans New Guinea family (Wurm 1982, Pawley 2006).

Mian has 13 consonantal phonemes /b, g, t, k, m, n, $\mathrm{y}, \mathrm{f}, \mathrm{s}, \mathrm{h}, \mathrm{l}, \mathrm{w}, \mathrm{j} /$ and ten vowel and diphthong phonemes $/ a, a^{\text {\& }}$ (i.e., pharyngealized a), $\varepsilon, i$, , , u; ai, ci, au, $\mathrm{ou} /$. Voiced stops are slightly pre-nasalized. Morphosyntactically, the language is head-marking with almost no nominal morphology, but complex, mainly suffixal verb morphology. Serial verb and clause chaining constructions are very common. SOV is the unmarked word order. ${ }^{2}$

Mian is a word-tone language, i.e., a lexical item is specified for one out of a set of five tonemes, which is assigned to the word as a whole. Tone is mainly used for lexical distinctions; it only plays a minor role in the marking of grammatical categories. The toneme inventory will be discussed in detail below.

In many noun-noun compounds, root tones exist peacefully side by side, e.g., if both roots are specified for low tone (throughout this paper capital letters are used to indicate underlying tone and accents are used to show pitch in phonetic representations):

\footnotetext{
${ }^{1}$ Note: 2006 affiliation. Affiliation as of publication: University of Surrey.

${ }^{2}$ All data was recorded by me during nine months of field work in New Guinea.
} 
Sebastian Fedden

(1)

$\begin{array}{llll}\text { Root 1: } & { }^{\mathrm{L}} \text { wan/ } & \text { [wàn] } & \text { 'bird' } \\ \text { Root 2: } & \text { LLam/ }^{\mathrm{L}} & \text { [àm] } & \text { 'house' } \\ \text { Compound: } & & \text { [wà.nàm] } & \text { 'bird house' }\end{array}$

Similarly, if the second root is specified for a contour tone, but the first root has a level tone:

$\begin{array}{llll}\text { Root 1: } & /{ }^{\mathrm{L}} \mathrm{wan} / & {[\text { wàn] }} & \text { 'bird' } \\ \text { Root 2: } & /^{\mathrm{LH}} \mathrm{a}^{\mathrm{Q}} \mathrm{n} / & {\left[\check{a ̆}^{\mathrm{S}} \mathrm{m}\right]} & \text { 'feather' } \\ \text { Compound: } & & \text { [wà.nă } & \text { 'bird feather' }\end{array}$

However, in compounds, in which the first root is specified for a contour tone, root tones form a composite tone pattern.

\begin{tabular}{|c|c|c|c|}
\hline Root 1: & $/{ }^{\mathrm{LH}} \mathrm{gaba}^{\mathrm{S}} \mathrm{m} /$ & {$\left[{ }^{\mathrm{y}} \mathrm{g} \partial ̀ . \beta \check{a}^{\text {r }} \mathrm{m}\right]$} & 'head' \\
\hline Root 2: & $/{ }^{\mathrm{L}} \mathrm{tol} /$ & [th̀̀l] & 'power' \\
\hline Compound: & $/{ }^{\mathrm{LH}} \mathrm{gaba}^{\mathrm{S}} \mathrm{m} /+/{ }^{\mathrm{L}} \mathrm{tol} /$ & 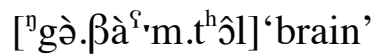 & \\
\hline
\end{tabular}

The tonal melody of the compound in (3) seems to preserve the linear order of root tones. Nothing is added and nothing is deleted, but tones do not align with the morphemes to which they originally belonged; the high pitch has moved to the second stem /tol/. Before I discuss the tonology of Mian compounds in more detail, I will give a short account of tone behavior in word-tone languages.

\section{Word-Tone}

In a typology of tone systems based on the domain of tonal contrast, Donohue (1997:373) distinguishes word-tone systems, which use the whole word as the relevant tone assignment domain, found e.g. in Mende (a Mande language from West Africa) and Shanghai (Sino-Tibetan), from syllable-tone systems, in which each syllable is allowed to bear a distinctive tone independent of the other syllables in the word, as for example in Mandarin, Cantonese (both Sino-Tibetan), Vietnamese (Mon-Khmer), Igbo (a Kwa language from West Africa), and Chuave (Papuan, Chimbu Province).

In a word-tone language, a limited number of lexically specified tone patterns account for the tonal surface specification of entire mono- and polysyllabic words. Mian has five underlying tonal melodies (which is a typical toneme inventory for a Papuan word-tone language): high $(\mathrm{H})$, low $(\mathrm{L})$, rising $(\mathrm{LH})$, peaking (LHL), and falling $(\mathrm{HL})$. L and LH are very common. $\mathrm{H}$ is somewhat less common and very rare in polysyllabic words. LHL is very rare on monosyllabic and disyllabic words. Finally, HL is very rare and does not appear on monosyllabic words at all. Table 1 gives on overview of distinctive Mian tonemes and their phonetic realization on mono- and disyllabic words. 
Table 1: Tonal minimal pairs

\begin{tabular}{|c|c|c|c|}
\hline \multicolumn{4}{|c|}{ Monosyllables } \\
\hline Toneme & Phonemic & Phonetic & Meaning \\
\hline $\mathrm{H}$ & $/{ }^{\mathrm{H}} \mathrm{an} /$ & [árn] & 'arrow; bow' \\
\hline $\mathrm{L}$ & /Lam/ & [àm] & 'house' \\
\hline $\mathrm{LH}$ & $\mathrm{LH}^{\mathrm{LH}} \mathrm{m} /$ & [ắ:m] & 'pandanus species' \\
\hline LHL & $/{ }^{\mathrm{LHL}} \mathrm{a}^{\mathrm{C}} \mathrm{m} /$ & {$\left[\hat{a}^{\mathrm{f}}: \mathrm{m}\right]$} & 'older sister' \\
\hline $\mathrm{H}$ & $/{ }^{\mathrm{H}} \mathrm{men} /$ & [mén] & 'child' \\
\hline $\mathrm{LH}$ & $/{ }^{\mathrm{LH}} \mathrm{men} /$ & [mě:n] & 'string bag' \\
\hline \multicolumn{4}{|c|}{ Disyllables } \\
\hline Toneme & Phonemic & Phonetic & Meaning \\
\hline $\mathrm{H}$ & $/{ }^{\mathrm{H}} \mathrm{seku} /$ & 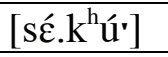 & 'bush knife' \\
\hline $\mathrm{L}$ & /Lafet/ & [à.fèt $\mathrm{t}^{\mathrm{h}}$ ] & 'different' \\
\hline $\mathrm{LH}$ & /LHafet/ & [à.f̌̌st $\left.\mathrm{t}^{\mathrm{h}}\right]$ & 'cleared of taboo' \\
\hline $\mathrm{L}$ & /Libal/ & [ì.ßßàl] & 'dust' \\
\hline LHL & $/{ }^{\mathrm{LHL}} \mathrm{ibal} /$ & [ì.ßâl] & 'paper wasp' \\
\hline $\mathrm{LH}$ & $/{ }^{\mathrm{LH}} \mathrm{usan} /$ & [ù.să:n] & 'vomit (n.)' \\
\hline $\mathrm{HL}$ & $/{ }^{\mathrm{HL}}$ usan/ & [ú.sân] & 'tail' \\
\hline
\end{tabular}

Table 2 shows the number of nouns occurring with a certain tonal specification out of a total of 200 monomorphemic native Mian nouns which I have used as data for the tone analysis.

Table 2: Toneme frequency

\begin{tabular}{|l|c|c|}
\hline & Monosyllables & Disyllables \\
\hline H & 21 & 2 \\
\hline L & 40 & 43 \\
\hline LH & 52 & 37 \\
\hline LHL & 1 & 3 \\
\hline HL & n/a & 1 \\
\hline
\end{tabular}

Tone assignment in monomorphemic Mian words can be modelled with the following autosegmental formalism (cf. Goldsmith 1990):

a) Only vowels are tone-bearing units (TBUs).

b) The penultimate tone in a melody is assigned to the TBU in the stressed syllable.

c) The last tone is assigned to the word-final TBU.

d) Remaining tones are mapped to TBUs on a one-to-one basis from left to right.

e) Leftover TBUs are assigned tone by spreading. 


\section{Sebastian Fedden}

There are two constraints on tone placement: First, the tonal melody a (lexical) word is specified for can maximally consist of 3 tones (MAX3) and second, contour tones are forbidden on non-final syllables (NOCONTOUR).

Stress and tone are distinct phenomena. The domain of stress in Mian is the word. Stress regularly falls on the final syllable in nouns, but can fall on the first syllable in disyllabic nouns if this syllable contains a pharyngealized /a/. As specified under (b) above, initial tone assignment depends on stress.

Stress behavior in Mian is an example of the complex interplay between segmental specification and prosody. A certain feature of a segment attracts stress which in turn attracts tone. A related phenomenon can be found in Warembori (probably Papuan but with strong Austronesian influence, north coast of Irian Jaya). Warembori (Donohue 1999:8-9) is not tonal but has two sets of nasal and voiced stops (a "normal" and a "heavy" set), which are pronounced the same but which have different effects on their segmental environment and on prosody; namely, a syllable with a consonant from the heavy series attracts stress.

Pharyngealization as an articulatory feature can be described as a gesture of the tongue root involving active retraction; the pharyngeal passage is narrower and the larynx slightly raised (Ladefoged and Maddieson 1996:306). The pharyngealized /a/ in Mian is distinct from the non-pharyngealized /a/ in that it has a noticeably lower fundamental frequency. Moreover, it is strongly associated with L or LH tonemes, has a lower third formant, and is noticeably longer in the same position and under the same tone. The pharyngealized /a/ as a phoneme is not quite as easy to establish than any of the other Mian segmental phonemes because the degree of pharyngealization varies greatly between speakers and there is only a handful of genuine minimal pairs (i.e. pairs which only differ in pharyngealization, not in tone or segmental make-up):

$$
\begin{aligned}
& \text { /al/ [àl] 'feces' } \\
& \text { /a } \left.{ }^{\S} 1 / \text { [à }{ }^{\mathrm{r}} \mathrm{l}\right] \text { 'skin' }
\end{aligned}
$$

The derivations in (5) and (6) below illustrate how underlying tones are assigned to mono-morphemic words by the formalism:

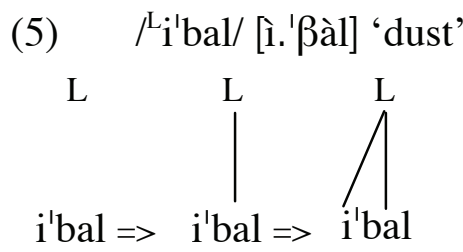




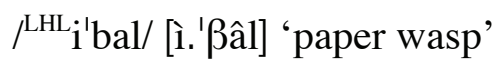

i'bal $\Rightarrow$ i'bal $\Rightarrow$ i'bal $\Rightarrow$ i'bal

\section{Mian Composite Tone}

As shown in (3) above, in some compounds the tonal melodies of both roots are preserved in linear order and form a composite tone pattern which is created by a process that looks like "tone shunting," set off by the language-specific constraint NOCONTOUR which outlaws tonal contours on non-final syllables. This process can be shown autosegmentally as follows (assuming for the moment that tone association takes place before compounding):

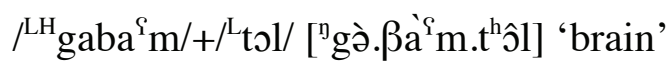

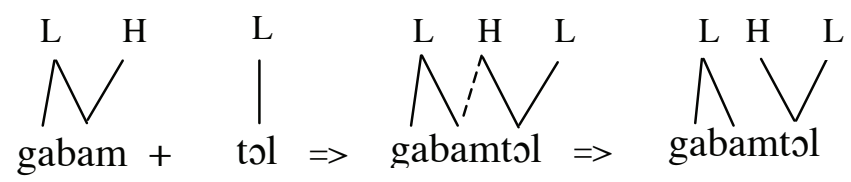

What the metaphor of "tone shunting" is supposed to capture is that tones (the train cars) are moved from one root (track 1) to another root (track 2) in the compound (the train station). In the process, tones are neither copied nor deleted, nor is their linear order altered. Changing the sequence of train cars on a given track might be possible, but cars do not duplicate, nor do they disappear when shunted. Other compounded nouns that behave identically are:

$$
\begin{aligned}
& \text { / }{ }^{\mathrm{LH}} \text { unan }+{ }^{\mathrm{L}} \mathrm{am} / \text { [ùnà.yâm] 'women's house' } \\
& \text { / }{ }^{\mathrm{LH}} \text { mil }+{ }^{\mathrm{L}} \mathrm{blon} / \text { [mìl.blôn] 'bean pod' } \\
& { }^{\mathrm{LH}} \text { fut }+{ }^{\mathrm{L}} \text { blon/ [fùt.blôn] 'cigarette pack' }
\end{aligned}
$$

Now, could this process of tonal change also be captured by a tone sandhi rule which spells out how the tonal specification of one root is changed due to the tonal specification of the other root in the complex word and vice versa? Sandhi rules are a common way of accounting for tonal change in compounds; see for example Newman and Petterson (1990) for Kairi (Papuan, Gulf Province) and Franklin (1971) for Kewa (Papuan, Enga Province). A possible sandhi solution would look like (9):

$$
\mathrm{LH}+\mathrm{L} \rightarrow \mathrm{L}+\mathrm{HL}
$$




\section{Sebastian Fedden}

Although such a solution is possible, it is not desirable for two reasons: (a) both root tones have to be altered when what happens is only the $\mathrm{H}$ somehow being moved to the right, and (b) sandhi rules are a much more powerful mechanism than is actually needed here because they commonly change tone identity and sequence, e.g. in processes of tone assimilation.

In the literature on compound tone behavior one finds another type, namely "tone deletion and spreading." For example, in the Papuan language Skou (Donohue 2003) the tones of one root are deleted and the melody of the other root is spread over the whole compound:
Root 1: $\quad /{ }^{\mathrm{HL}} \mathrm{ta} /$
'blade'
Root 2: $\quad$ / $\mathrm{H}$ ru/ 'handle'
Compound: $\quad /{ }^{\mathrm{HL}} \mathrm{tã}+{ }^{\mathrm{H}} \mathrm{rt} / \quad$ 'blade handle'

The derivation given by Donohue (2003:340) can be seen in (11):

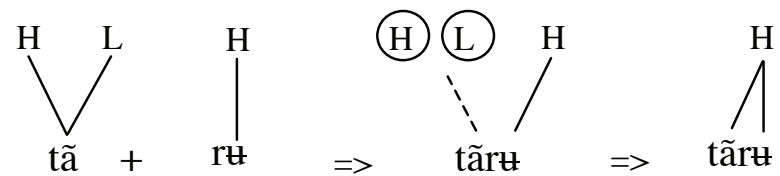

The result is something like a truncated composite tone where part of the melody is simply deleted. Logically, the result is that Skou compounds always have a melody that conforms to one of the basic tonal melodies for mono-morphemic Skou words. A similar situation can be found in Kuman (Papuan, Chimbu Province) described by Hardie (2003).

Looking at the Mian case again, it is conspicuous that-as in Skou-tone in compounds does not seem to respect morpheme boundaries. The composite tone spreads over the whole word and consists of a basic tonal melody which can also be found on mono-morphemic words, namely LHL (the peaking toneme); cf. ${ }^{\text {LHL }} \mathrm{ibal} /$ 'paper wasp' in example (6). If this composite melody is assigned to the whole compound directly, that is after compounding has taken place, the formalism specified above comes up with the correct result because stress placement in the compound makes sure that tone is assigned correctly to the compound as whole, as in (12):

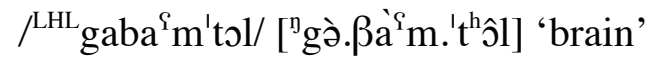

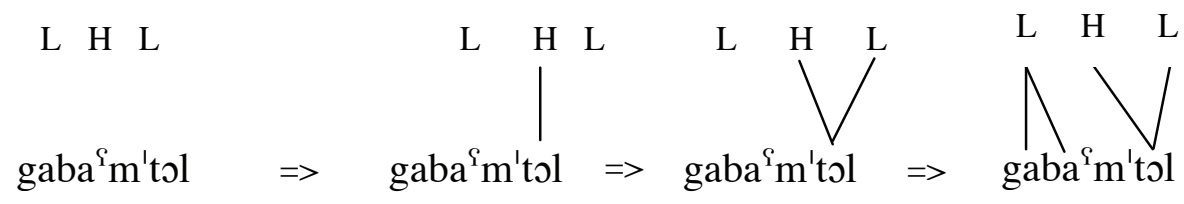




\section{Composite Tone in Mian Noun-Noun Compounds}

A similar solution can be found, when the second member in the compound bears a high tone, for example:

\begin{tabular}{|c|c|c|}
\hline $\begin{array}{l}\text { Root 1: } \\
\text { Root 2: } \\
\text { Compound: }\end{array}$ & $\begin{array}{l}/^{\mathrm{LH}} \mathrm{ba}^{\mathrm{S}} \mathrm{n} / \\
/^{\mathrm{H}} \mathrm{On} /\end{array}$ & 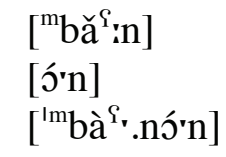 \\
\hline
\end{tabular}

The basic melody LH is assigned to the compounded word. Again, initial tone assignment is determined by stress.

$$
/^{\mathrm{LH}} \text { 'ba }{ }^{\mathrm{S}} \mathrm{n} \text { / } / \text { ["ma }^{\mathrm{Im}} \mathrm{a}^{\mathrm{S}} \cdot \text {.nó'n] 'jaw bone' }
$$
L H
L $\quad \mathrm{H}$
$\mathrm{L} \mathrm{H}$
'ba'non
$\Rightarrow \quad$ 'ba $^{\mathrm{S}}$ non $\quad \Rightarrow \quad$ 'ba'non

This is exactly parallel to the facts one finds in mono-morphemic words. Stress determines tone assignment. If the melody LH is assigned to the Mian word for 'woman', the result is [u'nă'n], but if this melody is assigned to the word for 'steel

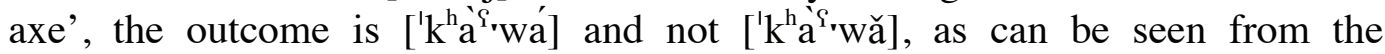
derivations in (15) and (16), respectively:

$$
\text { / LHu'nay / [ù.'nă'v] 'woman' }
$$

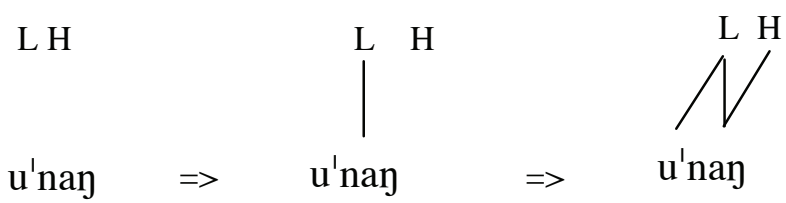

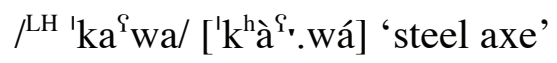

$\left.\left.{ }^{\prime} \mathrm{ka}^{\mathrm{q}} \mathrm{wa} \Rightarrow\right|^{\mathrm{kH}} \mathrm{ka}^{\mathrm{q}} \mathrm{wa} \quad \Rightarrow \quad\right|^{\mathrm{k} k{ }^{\mathrm{q}} \mathrm{wa}}$

So far the examples given suggest that situations in which tones do not respect morpheme boundaries are restricted to compounds in which the first root is specified for a contour tone. This, however, is not the case. 


\section{Sebastian Fedden}

\begin{tabular}{|c|c|c|}
\hline $\begin{array}{l}\text { Root 1: } \\
\text { Root 2: } \\
\text { Compound: }\end{array}$ & $\begin{array}{l}{ }^{\mathrm{L}} \operatorname{mian} / \\
{ }^{\mathrm{H}} \mathrm{t} \in \mathrm{n} /\end{array}$ & 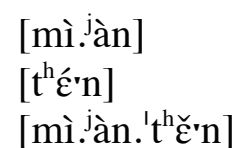 \\
\hline
\end{tabular}

In this case, root tone does not respect morpheme boundaries though the NoCONTOUR constraint is not violated. However, the resulting compound tone is not *[mi. ${ }^{\text {'an. }}$ 't $\left.^{\mathrm{h}} \varepsilon^{\prime} \mathrm{n}\right]$ 'Mian people'. Rather, there is a rising contour on the final syllable, which can be explained straightforwardly if it is assumed that a composite tone $\mathrm{LH}$, which is put together from the two root tones, is assigned to the whole compound, as in (18):

$$
{ }^{\mathrm{LH}} \operatorname{mian}{ }^{\prime} \operatorname{ten} / \text { [mi. Jàn.'thě'n] 'Mian people’ }
$$

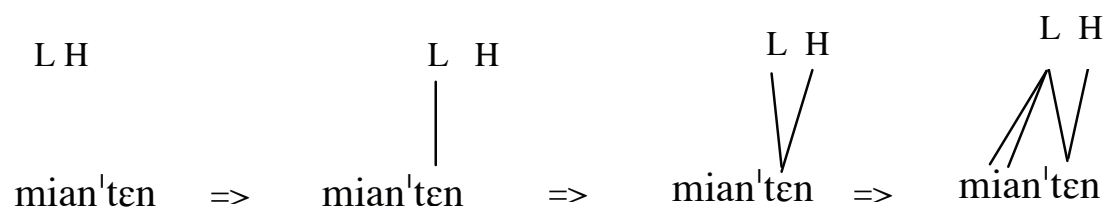

So there are two facts which seem to be quite strong evidence that in Mian the domain of lexically specified tone is the word, whether it is mono- or polymorphemic: (1) composite tone does not refer to morpheme boundaries within the compound, and (2) composite tone assignment is dependent on stress and stress is a feature of words in Mian.

To conclude, the domain of Mian composite tone is the word. Compounds are words and therefore should be treated as words. They belong into the lexicon together with their tonal specification.

\section{MAX3-Constraint Violations}

So far composite tone consists of maximally three tones and thus conforms to the MAX3 constraint. However, what happens if the composite tone melody violates this constraint? In other words, what if the composite melody consists of more than three tones?

Before looking at the more complicated aspects of Mian compound tonology, a word about tone pattern frequency is necessary: while the exact degree of productivity of compounding is hard to estimate at the present stage, it is safe to say that Mian has a sizable number of both noun-noun and verb-verb compounds (the latter not being the focus of this paper) and a limited number of compounds involving other parts of speech. However, there are fundamental differences in tone pattern frequency. All patterns in which the composite tone has three tonal elements or less are more or less common, whereas the ones with more than three are very rare, which is to be expected because they violate the MAX3 constraint. So far there are three different cases: 


\section{Composite Tone in Mian Noun-Noun Compounds}
a) $\mathrm{LHL}+\mathrm{L}$
${ }^{\mathrm{LHL}} \mathrm{kla}+{ }^{\mathrm{L}}$ ajam/
'very good' (very+good) $)^{3}$
b) $\mathrm{LH}+\mathrm{LH}$
${ }^{\mathrm{LH}}$ fut $+{ }^{\mathrm{LH}} \mathrm{a}^{\mathrm{S}} \mathrm{n} /$
'tobacco leaf; letter' (tobacco+leaf)
c) $\mathrm{LHL}+\mathrm{LH}$
${ }^{\mathrm{LHL}} \mathrm{ibal}+{ }^{\mathrm{LH}} \mathrm{a}^{\mathrm{S}} \mathrm{n} /$ 'paper wasp wing' (paper wasp+leaf)

In the following, each of these cases is examined individually. The derivation for the LHL+L case is given in (19):

$$
\begin{aligned}
& \text { / }{ }^{\mathrm{LHL}} \text { klajam/ [krà.'jâm] 'very good' } \\
& \text { L H L } \\
& \text { kla'jam } \Rightarrow \text { kla'jam } \Rightarrow \text { kla'jam }
\end{aligned}
$$

The compounded word has the basic melody LHL, which can be assigned straightforwardly to the word as a whole. However, the composite melody would have been LHL+L, but only LHL surfaces. This shows an important restriction on composite tone in Mian. In any tone sequence identical tones are fused. This tonal behavior is in accord with the Obligatory Contour Principle (OCP), originally proposed by Leben (1973), which rules out two identical autosegments following each other. To comply with the OCP, identical adjacent autosegments (tones, in this case), which end up next to each other due to morphological processes have to fuse into one before they are associated with elements on the segmental tier.

If two roots, each with a LH melody, are compounded, the composite melody is LHLH. However, this melody does not surface when the word is pronounced in isolation:

$$
/^{\mathrm{LHLH}_{\text {fu'ta }}}{ }^{\mathrm{S}} \mathrm{n} /\left[\text { fù. 't } \mathrm{tă}^{\mathrm{h}}{ }^{\mathrm{S}} \mathrm{n}\right] \text { 'tobacco leaf; letter' }
$$

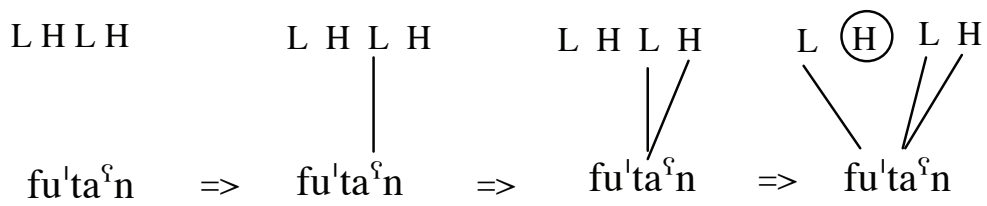

The first $\mathrm{H}$ remains floating and thus phonetically unrealized because there is no TBU left in the compound to which it could attach. The result is a complex word, which again conforms to the tonal restrictions of mono-morphemic words. However, when an inherently toneless article cliticizes to this word, the underlying composite melody LHLH surfaces again:

\footnotetext{
3 This is not a noun-noun compound but nonetheless an interesting case because of its tonal phonology.
} 


\section{Sebastian Fedden}

(21)

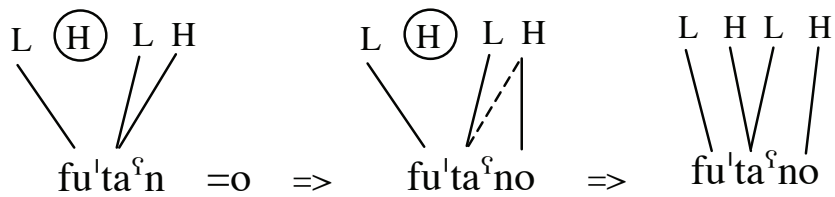

Obviously, the language takes great pains to preserve root tone in a composite melody LHLH even to the point of violating otherwise strong constraints, namely NOCONTOUR, which specifies that contours are only allowed on TBUs in final syllables. MAX3 appears also to be violated, but note that here the domain is a different one; we are not dealing with lexical words anymore but with prosodic words. Tonal behavior in the larger domain shows that the whole composite melody is preserved in the compound melody and that the compound has to be specified for the full composite melody LHLH. It might not be coincidence that it is the pharyngealized /a/ which carries the "illegal" second tone under these exceptional circumstances because it has the phonetic capability to do so due to its being longer than any other vowel phoneme.

In the third case LHL+LH, neighboring Ls are first fused to conform to the OCP and then the resulting composite melody LHLH is assigned to the compound. There is no violation of NoCONTOUR because the compound has enough TBUs to accommodate the whole composite melody.

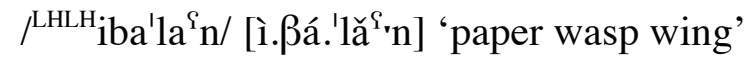

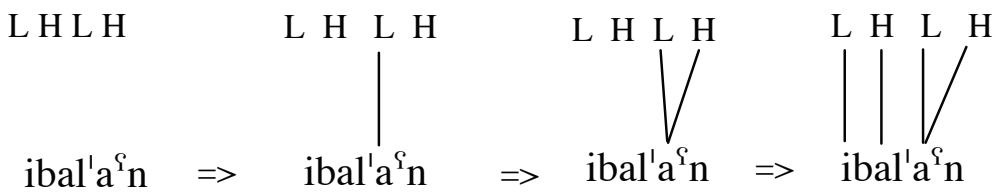

Although it seems that MAX3 has been violated, there is nothing in the derivation in (22) that suggests a violation of any constraint. The four tones in the composite melody can be assigned to the three TBUs in the compound without problem. Obviously, the constraint is formulated too strictly. Rather, there should be a MAX constraint which specifies that the number of tones in a melody may at least be one larger than the number of TBUs in the word.

\section{Summary}

Table 3 below gives an overview of root tone combinations in Mian noun-noun compounds. The table shows that the tonal melody in attested Mian compounds is in each case a composite melody consisting of the two root tones with any neighboring identical tones fused. The table contains two root tone combinations which have not been covered in detail in the course of this paper, namely $\mathrm{H}+\mathrm{L}$ 
Composite Tone in Mian Noun-Noun Compounds

and $\mathrm{H}+\mathrm{H}$, but resulting composite tone in both cases conforms to the predictions of the proposed analysis. (As the toneme HL is only attested in a single monomorphemic word, namely $/{ }^{\mathrm{HL}} \mathrm{usan} /$ [u'sân] 'tail', which has not yet been found as an element in a compound, it has not been included in the table. Black frames indicate that the pattern is so far unattested. Rare patterns are marked grey.)

Table 3: Root tone combinations in noun-noun compounds

\begin{tabular}{|c|c|c|c|c|}
\hline Root 2 & $\mathrm{~L}$ & $\mathrm{H}$ & LH & LHL \\
\hline $\mathrm{L}$ & $\begin{array}{c}\text { L } \\
\text { [wà.'nàm] } \\
\text { 'bird house' }\end{array}$ & $\begin{array}{c}\text { LH } \\
\text { [mì. 'àn.'thě'n] } \\
\text { 'Mian people' }\end{array}$ & $\begin{array}{c}\text { LH } \\
\text { [wà.nă' 'n] } \\
\text { 'feather' }\end{array}$ & \\
\hline $\mathrm{H}$ & $\begin{array}{c}\text { HL } \\
\text { [án.'wâl] } \\
\text { 'bow string' }\end{array}$ & $\begin{array}{c}\mathrm{H} \\
\text { [bá.'nón] } \\
\text { 'arm bone' }\end{array}$ & & \\
\hline LH & 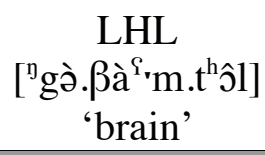 & $\begin{array}{c}\text { LH } \\
{\left[{ }^{\left.\text {Imbà }{ }^{9} \cdot n o ́ ' n\right]}\right.} \\
\text { 'jaw bone' }\end{array}$ & $\begin{array}{l}\mathrm{L}(\mathrm{H}) \mathrm{LH} \\
\text { [fù.'thă } \mathrm{t}^{\mathrm{f} \cdot \mathrm{n}]} \\
\text { 'letter' }\end{array}$ & \\
\hline LHL & $\begin{array}{l}\text { LHL } \\
\text { [krà'jâm] } \\
\text { 'very good' }\end{array}$ & & $\begin{array}{c}\text { LHLH } \\
\text { [ì./ál.'ǎ 'n] } \\
\text { 'paper wasp wing' }\end{array}$ & \\
\hline
\end{tabular}

\section{Conclusion and Further Research}

This paper tried to show that the domain for tone assignment in Mian is the word, not the morpheme. Tonal melodies ignore morpheme boundaries in compounds. The result is composite tone which is assigned to mono- and polymorphemic words on the basis of word stress. The main difference between Mian and a language like Skou — in my analysis - is that in Skou, compound tone melodies always have to conform to tonemes which can also be found on monomorphemic words, whereas Mian does not have this restriction. Mian is an interesting case in that it wants root tones in some compounds to be preserved even if this leads to the violation of otherwise important constraints. However, basically Mian composite tone is word-tone.

This preliminary analysis of composite tone behavior in Mian noun-noun compounds is only a first step towards a fuller understanding of Mian tonology in complex words and across word boundaries. Further research will concentrate heavily on (a) verb tone, especially tone in verb-verb compounds, (b) the extent to which MAX-violating composite tone actually occurs in the language, and (c) the question as to whether the assumption of word stress as the decisive prosodic feature which determines initial tone assignment is tenable. 
Sebastian Fedden

\section{References}

Donohue, Mark. 1997. Tone Systems in New Guinea. Linguistic Typology $1(3): 374-386$.

Donohue, Mark. 1999. Warembori. Languages of the World/Materials 341. Muenchen: Lincom Europa.

Donohue, Mark. 2003. The Tonal System of Skou, New Guinea. In K. Shigeki, ed., Proceedings of the Symposium Cross-linguistic Studies of Tonal Phenomena: Historical Development, Phonetics of Tone, and Descriptive Studies. Tokyo University of Foreign studies: Research Institute for Language and Cultures of Asia and Africa, 329-365.

Franklin, Karl. 1971. A Grammar of Kewa, New Guinea. Pacific Linguistics, C16. Canberra: Australian National University.

Goldsmith, John. 1990. Autosegmental and Metrical Phonology. Oxford: Blackwell.

Hardie, Peter. 2003. Is Kuman Tonal?. MA sub-thesis. Canberra: Australian National University.

Healey, Alan. 1964. A Survey of the Ok Family of Languages; Reconstructing Proto-Ok. Part of Ph.D. diss., Canberra: Australian National University.

Ladefoged, Peter, and Ian Maddieson. 1996. The Sounds of the World's Languages. Oxford: Oxford University Press.

Leben, William. 1973. Suprasegmental Phonology. Ph.D. diss., MIT.

Newman, John, and Robert Petterson. 1990. The Tones of Kairi. Oceanic Linguistics 29(1):49-76.

Pawley, Andrew. 2006. The Chequered Career of the Trans New Guinea hypothesis: Recent Research and its Implications. In A. Pawley, R. Attenborough, J. Golson and R. Hide, eds., Papuan Pasts: Cultural, Linguistic and Biological Histories of Papuan-speaking Peoples, 67-108, Canberra: Pacific Linguistics.

Wurm, Stephen. (1982): Papuan Languages of Oceania. Tuebingen: Narr.

Sebastian Fedden

Surrey Morphology Group

School of English and Languages

University of Surrey

Guildford GU2 7XH

United Kingdom

s.fedden@surrey.ac.uk 